\title{
Morphological Characterization and Determination of Aflatoxin-Production Potentials of Aspergillus flavus Isolated from Maize and Soil in Kenya
}

\author{
Matome Gabriel Thathana ${ }^{1}$, Hunja Murage ${ }^{2}$, Akebe Luther King Abia ${ }^{3}$ (D) and Michael Pillay ${ }^{1, *}$ \\ 1 Department of Biotechnology, Vaal University of Technology, Private Bag X021, Vanderbijlpark 1911, \\ South Africa; matomet@vutcloud.onmicrosoft.com \\ 2 Department of Horticulture, Jomo Kenyatta University of Agriculture and Technology, P.O. Box 62000-00200, \\ Juja 0561, Kenya; hunjamurage@gmail.com \\ 3 AMBIO Environmental Management, Department of Biotechnology, Vaal University of Technology, \\ Private Bag X021, Vanderbijlpark 1911, South Africa; lutherkinga@yahoo.fr \\ * Correspondence: mpillay@vut.ac.za; Tel.: +27-(0)16-950-9614
}

Received: 3 July 2017; Accepted: 7 September 2017; Published: 21 September 2017

\begin{abstract}
This study aimed at morphologically identifying Aspergillus flavus in soil and maize and at determining their aflatoxin-producing potentials. Five hundred and fourteen isolates obtained from maize and soil in Kenya were cultivated on Czapeck Dox Agar, Malt Extract Agar, Sabouraud Dextrose Agar, Potato Dextrose Agar, and Rose-Bengal Chloramphenicol Agar. Isolates were identified using macro-morphological characteristics. Micromorphological characteristics were determined using slide cultures. Aflatoxin production was determined by direct visual determination of the UV fluorescence of colonies on Coconut Agar Medium, Yeast Extract Sucrose agar, and Yeast Extract Cyclodextrin Sodium Deoxycholate agar and by Thin Layer Chromatography. Forty-three presumptive A. flavus isolates were identified; aflatoxin was detected in $23 \%$ of the isolates by UV fluorescence screening and in $30 \%$ by Thin-Layer Chromatography (TLC). The aflatoxins produced were: aflatoxin $B_{1}\left(A F B_{1}\right)$, aflatoxin $B_{2}\left(A F B_{2}\right)$, and aflatoxin $G_{1}\left(A_{F} G_{1}\right)$; some isolates produced only $A F B_{1}$, whereas others produced either $A F B_{1}$ and $A F B_{2}$ or $A F B_{1}$ and $A F G_{1}$. The highest incidence of $A$. flavus $(63 \%)$ and aflatoxin production $(28 \%)$ was recorded in samples from Makueni District. Isolates from Uasin Gishu (21\%) and Nyeri (5\%) were non-aflatoxigenic. Bungoma District recorded $11 \%$ positive isolates of which $2 \%$ were aflatoxin producers. The occurrence of aflatoxin-producing $A$. flavus emphasises the need for measures to eliminate their presence in food crops.
\end{abstract}

Keywords: Aflatoxins; Aspergillus flavus; morphological characterization; Thin Layer Chromatography; UV Fluorescence

\section{Introduction}

Aspergillus flavus is a ubiquitous and cosmopolitan filamentous fungus known to proliferate in a wide range of environmental conditions [1]. It is both a saprophytic and an opportunistic pathogen and thrives abundantly on many organic nutrient sources with monosaccharides and disaccharides [2]. According to Hell and Mutegi [3] and Yu [4], species of the Aspergillus section Flavi have the ability to survive temperatures ranging from $12{ }^{\circ} \mathrm{C}$ to $48{ }^{\circ} \mathrm{C}$, with the optimal growth temperature ranging from $28{ }^{\circ} \mathrm{C}$ to $37^{\circ} \mathrm{C}$, with a high humidity of above $80 \%$. Although encountered mostly as a storage mold on plant products, A. flavus invades and infects developing maize seeds in the field before harvest and mature seeds during harvest and in storage [5].

Members of the genus Aspergillus, the taxonomy of which is complex and continuously evolving, are characterized by vesicle-bearing conidiophore [6]. Several taxonomic keys and guidelines have 
been developed for the elucidation of the morphological features of Aspergillus species. Seriation, the shape and size of the vesicle, conidia, and stipe, the presence of Hülle cells, and the morphology of cleistothecia and ascospores are the microscopic features used for species characterization, while the macroscopic features include conidial and mycelial colour, colony diameter, colony reverse colour, the production of exudates and soluble pigments, and the presence of sclerotia and cleistothecia [7-9].

The growth of $A$. flavus and the subsequent production of aflatoxins on crops have adverse health implications for humans and animals [10]. Aflatoxin $B_{1}\left(\mathrm{AFB}_{1}\right)$, aflatoxin $\mathrm{B}_{2}\left(\mathrm{AFB}_{2}\right)$, aflatoxin $\mathrm{G}_{1}\left(\mathrm{AFG}_{1}\right)$, and aflatoxin $\mathrm{G}_{2}\left(\mathrm{AFG}_{2}\right)$ are the most important of the 18 aflatoxins known [11]. Their consumption results in chronic effects such as immune suppression, impaired child growth, abnormal foetal development, and cancer and acute effects such as hepatitis and jaundice, abnormal swellings, and even death [2].

Cases of human and animal aflatoxicosis have been reported in Africa as a result of the consumption of food and feed contaminated with aflatoxins [12]. In Kenya, aflatoxin contamination of maize, the country's most dominant subsistence and commercial crop, has repeatedly resulted in serious health implications. Of the recurrent outbreaks of human aflatoxicosis reported between 1978 and 2008, the most severe one was in 2004, during which 317 cases and 125 deaths were reported [12,13]. To date, aflatoxin contamination continues to be a problem for subsistence farmers in Kenya because no precautionary measures are routinely adopted to keep in check the fungal infection of crops. Therefore, continuous monitoring of crops intended for food and feed is highly important. The main objective of this study was to identify and determine the aflatoxin production potential of $A$. flavus isolated from maize and soil in Kenya.

\section{Materials and Methods}

\subsection{Morphological Characterization of Aspergillus flavus}

Five hundred and fourteen pure cultures of fungal isolates were obtained from the Jomo Kenyatta University of Agriculture and Technology in Kenya. They were previously isolated from maize and soil obtained from maize farms and rural households in the Makueni, Nyeri, Bungoma, and Uasin Gishu districts of Kenya, as described by Odhiambo et al. [14]. The samples were received as spore suspensions in $2 \mathrm{~mL}$ sterile microfuge tubes. Upon receipt, the isolates were cultivated on Czapeck Dox Agar (CZA), Malt Extract Agar (MEA), Sabouraud Dextrose Agar (SDA), Potato Dextrose Agar (PDA), and Rose Bengal Chloramphenicol Agar (RBCA). Ten microliters of each of the isolate's spore suspensions were aseptically inoculated in triplicates at the centre of Petri plates containing each of the culture media. The plates were then incubated at $27^{\circ} \mathrm{C}$ for seven days in the dark. The key descriptions of Klich [8] and Clayton [15] were then employed for further verification of their morphological characteristics. Macroscopic characteristics such as colony growth, colony colour, colony texture, colony reverse, and the presence of exudates were studied. For microscopic analysis, characteristics such as conidiophores, vesicles, matulae, phialides, and conidia were examined. Riddell's classic slide culture method [16] and a method described by Diba et al. [9] were used for the cultivation of the isolates on the microscopic slides. Once prepared, the slides were then examined under a Motic BA210 Basic Biological Light Microscope (Motic Instruments Inc., Richmond, BC, Canada) using the immersion oil $(100 \times)$ objective.

\subsection{Determination of Aflatoxin-Production Potential of A. flavus}

\subsubsection{Cultural Screening for Aflatoxin Production}

Coconut Agar Medium (CAM), Yeast Extract Sucrose agar (YES) and Yeast Extract Cyclodextrin Sodium Deoxycholate agar (YCSD) were used to screen for the isolates' ability to produce aflatoxins in order to differentiate between the aflatoxin-producing and non-producing isolates. YES, YCSD, and CAM were prepared in glass Petri dishes, as described by Davis et al. [17], Fente et al. [18], 
and Davis et al. [19], respectively. Ten microliters of each of the isolate's spore suspension was aseptically inoculated in triplicates at the centre of Petri plates containing each of these media. The plates were then incubated at $27^{\circ} \mathrm{C}$ for seven days in the dark. Following incubation, the plates were then observed under UV light $(365 \mathrm{~nm})$ in the dark for fluorescence screening of aflatoxins, and the results were recorded.

\subsubsection{Aflatoxin Extraction and Thin Layer Chromatography}

After fluorescence screening for aflatoxin production on YES, YCSD, and CAM, the whole content of each Petri dish (agar, mycelia, and spores) was cut into pieces and aflatoxin extraction was performed following the methods described by Younis and Malik [20] and Ramesh et al. [21]. Then, $5 \mu \mathrm{L}$ of the aflatoxin extracts were spotted on thin-layer chromatography silica gel $60 \mathrm{~F}_{254}$ plates (Merck, Darmstadt, Germany). The plates were developed in mobile phase consisting of chloroform: acetone solution (85:15) for $60 \mathrm{~min}$. They were then left to air dry for $5 \mathrm{~min}$ and visualized under long wavelength ultraviolet (UV) light $(365 \mathrm{~nm}$ ) for the presence of blue (AFB1 and AFB2) and green (AFG1 and AFG2) fluorescent spots. The retardation factor (Rf) values were calculated and compared to the Rf values of the aflatoxin standards previously obtained by Younis and Malik [20]. One morphologically characterized Penicillium sp. was used as a negative control in the experiment.

\section{Results}

\subsection{Identification of Aspergillus flavus Isolates}

Forty-three A. flavus isolates were identified from the fungal cultures previously isolated from maize kernels and soil in Kenya. They were identified through the examination of their morphological features as per the key descriptions recommended by Klich [8] and Clayton [15]. The percentage detections of the isolates in Makueni, Uasin Gishu, Bungoma, and Nyeri were 63\%, 21\%, 11\%, and $5 \%$, respectively.

\subsection{Phenotypic Characterization of the Aspergillus flavus Isolates}

\subsubsection{Macroscopic Characteristics of the Isolates on PDA}

The colony morphology of A. flavus on the different culture media is shown in Figure 1.

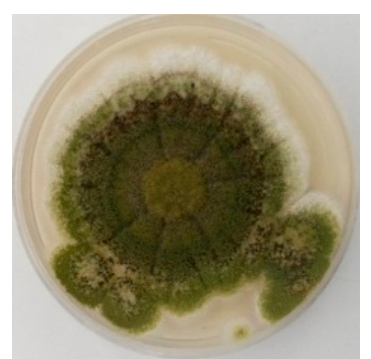

(A)

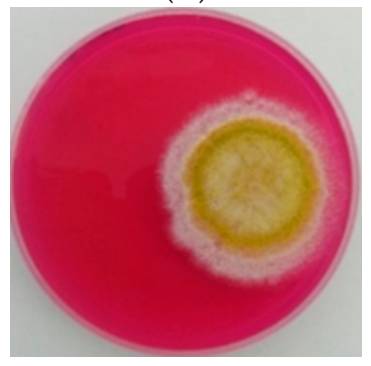

(C)

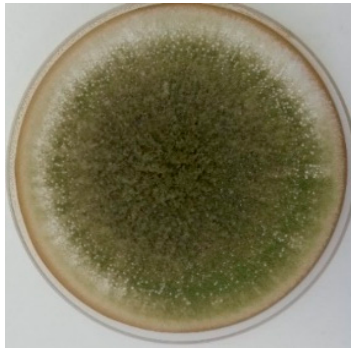

(B)

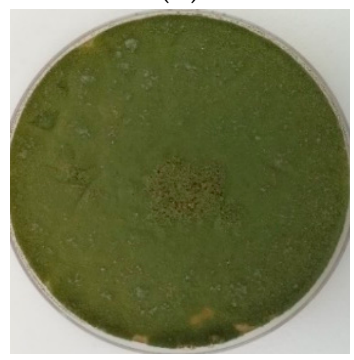

(D)

Figure 1. Cont. 


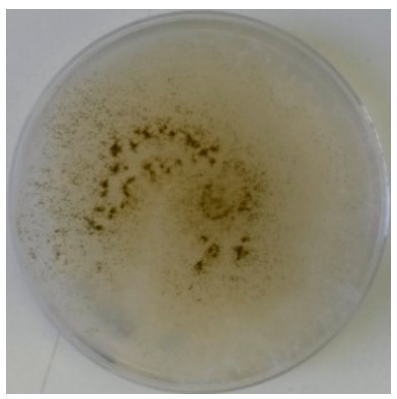

(E)

Figure 1. Colony morphology of isolate EM1811 on (A) Potato Dextrose Agar (PDA); (B) Sabouraud Dextrose Agar (SDA); (C) Rose Bengal Chloramphenicol Agar (RBCA); (D) Malt Extract Agar (MEA); and (E) Czapeck Dox Agar (CZA).

Figure 1A gives a representation of the colony characteristics of $A$. flavus on PDA. Initially, the isolates acquired the white colour of the mycelia. After three days, the isolates produced olive and dark green conidia, which then dominated colony appearance. They were commonly plain and flat at the edges but were raised in the centre and wrinkled in an almost cerebriform pattern. All the isolates produced exudates (droplets of liquid), which were either uncoloured or brown. The sclerotia, which are the compact mass of hardened fungal mycelia, were produced in 16 isolates and were deep brown in color. The colonies were encircled by a white border, and the colony diameter ranged between 65 and $75 \mathrm{~mm}$. The undersides of the colonies were slightly pale.

\subsubsection{Macroscopic Characteristics of the Isolates on SDA}

The colonies on SDA (Figure 1B) were initially white and had a soft velvety surface. After four days of growth, the colonies became raised and turned floccose at the centre, with some isolates deeply floccose. During sporulation, the colonies produced yellowish-green and olive conidia. The conidia covered the entire surface of the colonies except for the edges, where a white border was produced. The white border then disappeared as the colonies became larger and produced more conidia. Sclerotia were produced and were initially white and turned deep brown on the sixth day of incubation. No exudates were produced. The reverse sides of the colonies were furrowed and slightly pale brown. The colony diameter on SDA ranged between 55 and $75 \mathrm{~mm}$.

\subsubsection{Macroscopic Characteristics of the Isolates on RBCA}

On RBCA (Figure 1C), the isolates first produced white floccose mycelia, which were smooth and raised. They then produced dull yellow conidia, which turned olive and dark green after six days. No sclerotia were produced. Exudates were produced and appeared as tiny uncoloured liquid droplets embedded within the mycelia. The isolates did not produce any soluble pigments, and the reverse sides of the colonies on RBCA were uncoloured. The diameter of the colonies ranged between 50 and $70 \mathrm{~mm}$.

\subsubsection{Macroscopic Characteristics of the Isolates on MEA}

Cultivation of the isolates on MEA resulted in colonies that had variable shapes and sizes (Figure 1D). Colony growth started with the production of smooth white mycelia. During sporulation, the isolates produced olive and dark green conidia. Sclerotia were produced in nine isolates and were white and deep brown. The isolates also produced uncoloured exudates, which were especially visible at the centre of the colonies. No soluble pigments were produced, and the undersides of the colonies were pale or light brown. 


\subsubsection{Macroscopic Characteristics of the Isolates on CZA}

When cultivated on CZA, the isolates produced white mycelia, which were flat and inconspicuous (Figure 1E). The isolates produced very few conidia, which were dull yellow and olive. After sporulation, some isolates produced large raised tufted wool of white mycelia. The colonies of all isolates appeared dry, and exudates and sclerotia were not produced. No soluble pigments were observed, and the undersides of the colonies were uncoloured.

\subsection{Microscopic Characteristics of the A. flavus Isolates}

To ascertain their precise identification, the microscopic characteristics (conidiophores, vesicles, metulae, phialides, and conidia) of these isolates were also examined (Figure 2).

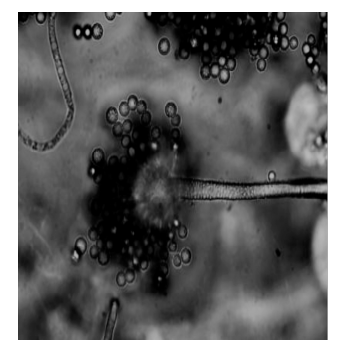

(A)

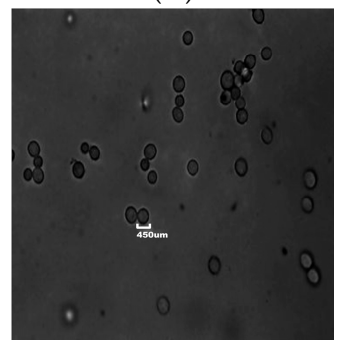

(C)

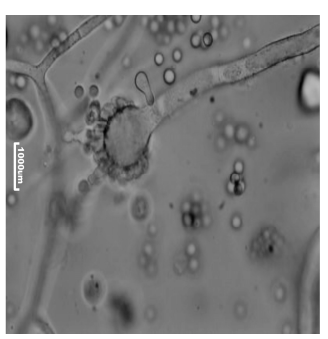

(B)

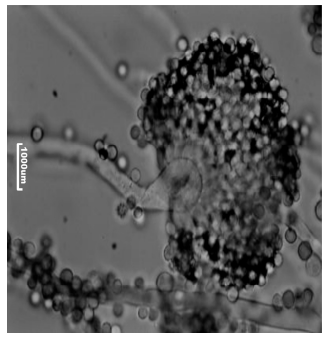

(D)

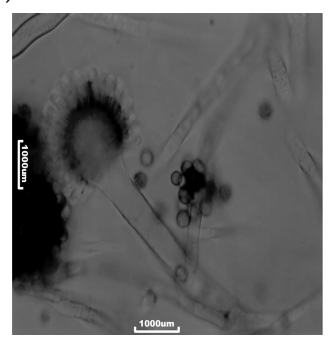

(E)

Figure 2. Microscopic characteristics of A. flavus isolates (A) EM167; (B-D) EM 184; and (E) EM 213 under the $100 \times$ objective of the Motic BA210 Basic Biological Light Microscope.

The conidiophores were uncoloured, thick walled, and coarsely roughened or pitted and were vesicle bearing. Their diameter ranged between 800 and $1200 \mu \mathrm{m}$. The vesicles were subglobose in some isolates and globose in others and were also variable in diameter, ranging between 1800 and 2000 $\mu \mathrm{m}$. The cells were either uniseriate or biseriate or both. For biseriate cells, the phialides were borne on the metuale, and, in uniseriate cells, they were attached directly to the vesicles. The metulae covered nearly the entire surface of the vesicles and radiated from the vesicles in all directions. The conidia were globose with thin walls, which were slightly roughened and ranged between 250 and $450 \mu \mathrm{m}$ in diameter. 


\subsection{Fluorescence Screening of Aflatoxins}

Figure 3 is a representation of the results obtained from the UV fluorescence screening of the A. flavus, showing both fluorescent and non-fluorescent isolates on YES (A and D), YCSD (B and E), and CAM (C and F).

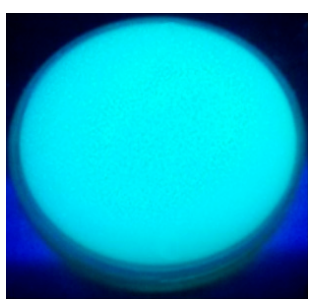

(A)

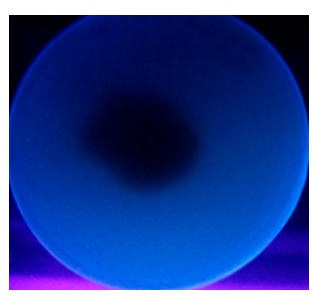

(D)

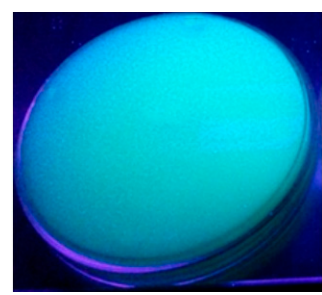

(B)

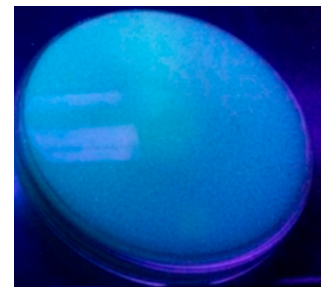

(E)

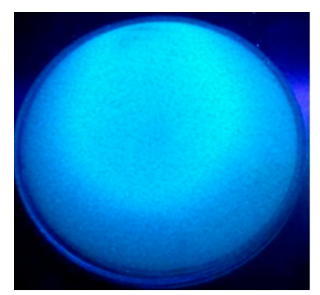

(C)

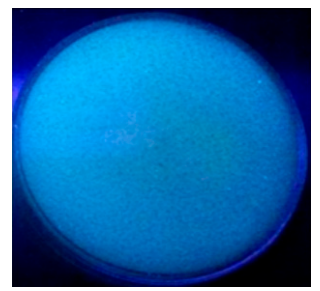

(F)

Figure 3. Colonies of aflatoxigenic (fluorescent) and non-aflatoxigenic (non-fluorescent) strains of A. flavus observed under UV light $(365 \mathrm{~nm})$ after seven days of growth on (A,D) Yeast Extract Sucrose agar (YES); (B,E) Yeast Extract Cyclodextrin Sodium Deoxycholate agar (YCSD); and (C,F) Coconut Agar Medium (CAM).

It was found that $10(23 \%)$ of the 43 isolates fluoresced blue on YES, YCSD, and CAM when exposed to UV light $(365 \mathrm{~nm})$, indicating their ability to produce aflatoxins. No fluorescence was detected in $33(77 \%)$ isolates, and this implied that they were non-aflatoxigenic.

\subsection{Thin-Layer Chromatography Detection of Aflatoxins}

The aflatoxin-producing ability of the A. flavus isolates in this study was further analysed using TLC. Using this chromatographic method, it was found that $13(30 \%)$ of the 43 isolates were aflatoxin producers, while the remaining $30(70 \%)$ isolates did not have aflatoxin-production potentials (Table 1). Of these 13 isolates, 10 were isolates that tested positive for aflatoxin production during fluorescence screening on YES, YCSD, and CAM.

Table 1. Identification of aflatoxin production through UV fluorescence screening and ThinLayer Chromatography.

\begin{tabular}{|c|c|c|c|c|c|c|c|}
\hline \multicolumn{2}{|c|}{ Isolate } & \multicolumn{3}{|c|}{ UV Fluorescence } & \multicolumn{3}{|c|}{ TLC } \\
\hline ID * & No. & YES & YCSD & CAM & Aflatoxin & Rf Value & Type \\
\hline EM 184 & 1 & + & + & + & + & 0.60 & B1 \\
\hline EM 156 & 2 & - & - & - & - & $\mathrm{n} / \mathrm{a}$ & $\mathrm{n} / \mathrm{a}$ \\
\hline EM 323 & 3 & - & - & - & + & 0.60 & B1 \\
\hline BS 042 & 4 & - & - & - & - & $\mathrm{n} / \mathrm{a}$ & $\mathrm{n} / \mathrm{a}$ \\
\hline NS 102 & 5 & - & - & - & - & $\mathrm{n} / \mathrm{a}$ & $\mathrm{n} / \mathrm{a}$ \\
\hline EM 167 & 6 & - & - & - & + & $0.60 ; 0.55$ & $\mathrm{~B} 1 ; \mathrm{B} 2$ \\
\hline EM 213 & 7 & + & + & + & + & 0.60 & B1 \\
\hline EM 291 & 8 & - & - & - & + & $0.60 ; 0.55$ & $\mathrm{~B} 1 ; \mathrm{B} 2$ \\
\hline EM 214 & 9 & + & + & + & + & $0.60 ; 0.50$ & $\mathrm{~B} 1 ; \mathrm{G} 1$ \\
\hline EM 232 & 10 & + & + & + & + & $0.60 ; 0.50$ & $\mathrm{~B} 1 ; \mathrm{G} 1$ \\
\hline EM 257 & 11 & + & + & + & + & $0.60 ; 0.50$ & B1; G1 \\
\hline
\end{tabular}


Table 1. Cont.

\begin{tabular}{|c|c|c|c|c|c|c|c|}
\hline \multicolumn{2}{|c|}{ Isolate } & \multicolumn{3}{|c|}{ UV Fluorescence } & \multicolumn{3}{|c|}{ TLC } \\
\hline ID * & No. & YES & YCSD & CAM & Aflatoxin & Rf Value & Type \\
\hline EM 189 & 12 & - & - & - & - & $\mathrm{n} / \mathrm{a}$ & $\mathrm{n} / \mathrm{a}$ \\
\hline EM 262 & 13 & - & - & - & - & $\mathrm{n} / \mathrm{a}$ & $\mathrm{n} / \mathrm{a}$ \\
\hline EM 1811 & 14 & - & - & - & - & $\mathrm{n} / \mathrm{a}$ & $\mathrm{n} / \mathrm{a}$ \\
\hline EM 141 & 15 & - & - & - & - & $\mathrm{n} / \mathrm{a}$ & $\mathrm{n} / \mathrm{a}$ \\
\hline EM 014 & 16 & - & - & - & - & $\mathrm{n} / \mathrm{a}$ & $\mathrm{n} / \mathrm{a}$ \\
\hline EM 112 & 17 & - & - & - & - & $\mathrm{n} / \mathrm{a}$ & $\mathrm{n} / \mathrm{a}$ \\
\hline EM 164 & 18 & - & - & - & - & $\mathrm{n} / \mathrm{a}$ & $\mathrm{n} / \mathrm{a}$ \\
\hline EM 301 & 19 & - & - & - & - & $\mathrm{n} / \mathrm{a}$ & $\mathrm{n} / \mathrm{a}$ \\
\hline EM 256 & 20 & - & - & - & - & $\mathrm{n} / \mathrm{a}$ & $\mathrm{n} / \mathrm{a}$ \\
\hline EM 226 & 21 & - & - & - & - & $\mathrm{n} / \mathrm{a}$ & $\mathrm{n} / \mathrm{a}$ \\
\hline EM 165 & 22 & + & + & + & + & $0.60 ; 0.50$ & B1; G1 \\
\hline EM 263 & 23 & - & - & - & - & $\mathrm{n} / \mathrm{a}$ & $\mathrm{n} / \mathrm{a}$ \\
\hline EM 324 & 24 & - & - & - & - & $\mathrm{n} / \mathrm{a}$ & $\mathrm{n} / \mathrm{a}$ \\
\hline BM 092 & 25 & - & - & - & - & $\mathrm{n} / \mathrm{a}$ & $\mathrm{n} / \mathrm{a}$ \\
\hline RM 187 & 26 & - & - & - & - & $\mathrm{n} / \mathrm{a}$ & $\mathrm{n} / \mathrm{a}$ \\
\hline EM 251 & 27 & - & - & - & - & $\mathrm{n} / \mathrm{a}$ & $\mathrm{n} / \mathrm{a}$ \\
\hline BS 033 & 28 & - & - & - & - & $\mathrm{n} / \mathrm{a}$ & $\mathrm{n} / \mathrm{a}$ \\
\hline EM 126 & 29 & + & + & + & + & $0.60 ; 0.50$ & B1; G1 \\
\hline RS 022 & 30 & - & - & - & - & $\mathrm{n} / \mathrm{a}$ & $\mathrm{n} / \mathrm{a}$ \\
\hline BS 116 & 31 & + & + & + & + & $0.60 ; 0.55$ & $\mathrm{~B} 1 ; \mathrm{B} 2$ \\
\hline EM 181 & 32 & + & + & + & + & 0.60 & B1 \\
\hline BS 142 & 33 & - & - & - & - & $\mathrm{n} / \mathrm{a}$ & $\mathrm{n} / \mathrm{a}$ \\
\hline RS 174 & 34 & - & - & - & - & $\mathrm{n} / \mathrm{a}$ & $\mathrm{n} / \mathrm{a}$ \\
\hline BS 023 & 35 & - & - & - & - & $\mathrm{n} / \mathrm{a}$ & $\mathrm{n} / \mathrm{a}$ \\
\hline RS 043 & 36 & - & - & - & - & $\mathrm{n} / \mathrm{a}$ & $\mathrm{n} / \mathrm{a}$ \\
\hline RS 061 & 37 & - & - & - & - & $\mathrm{n} / \mathrm{a}$ & $\mathrm{n} / \mathrm{a}$ \\
\hline NS 182 & 38 & - & - & - & - & $\mathrm{n} / \mathrm{a}$ & $\mathrm{n} / \mathrm{a}$ \\
\hline RS 013 & 39 & - & - & - & - & $\mathrm{n} / \mathrm{a}$ & $\mathrm{n} / \mathrm{a}$ \\
\hline RS 063 & 40 & - & - & - & - & $\mathrm{n} / \mathrm{a}$ & $\mathrm{n} / \mathrm{a}$ \\
\hline EM 223 & 41 & + & + & + & + & 0.60 & B1 \\
\hline EM 265 & 42 & - & - & - & - & $\mathrm{n} / \mathrm{a}$ & $\mathrm{n} / \mathrm{a}$ \\
\hline RS 114 & 43 & - & - & - & - & $\mathrm{n} / \mathrm{a}$ & $\mathrm{n} / \mathrm{a}$ \\
\hline RS $062 * *$ & 44 & - & - & - & - & $\mathrm{n} / \mathrm{a}$ & $\mathrm{n} / \mathrm{a}$ \\
\hline
\end{tabular}

The distribution of aflatoxigenic and non-aflatoxigenic $A$. flavus isolates in four maize-growing districts of Kenya are presented in Figure 4.

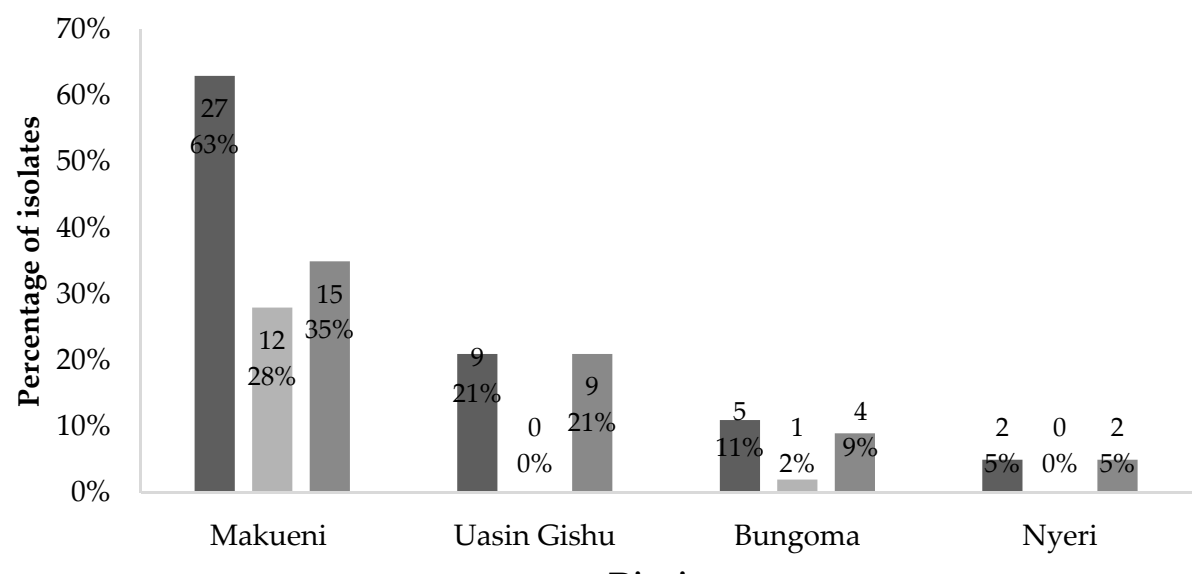

\section{Districts}

Total $\square$ Aflatoxigenic $\quad$ Non-aflatoxigenic

Figure 4. The occurrence of $A$. flavus and the distribution of aflatoxin production in four maize-growing districts in Kenya. 
Of the 27 isolates from Makueni, $12(28 \%)$ were aflatoxigenic and $15(35 \%)$ were non-aflatoxigenic. Aflatoxin was not detected in all the A. flavus isolates identified from Uasin Gishu and Nyeri. Only one $(2 \%)$ of the isolates identified from Bungoma displayed aflatoxin producing capability, and four $(9 \%)$ tested negative.

\section{Discussion}

\subsection{Incidence of A. flavus across the Four Maize Growing Districts in Kenya}

In Kenya, maize is widely grown under diverse environmental conditions. When grown under unfavourable conditions, it can, like any other crop, be affected by many diseases and pests. Aspergillus flavus has long been recognized as one of the major fungal diseases of maize. The fungus infects and contaminates maize both in the field and during storage, and the incidence of contamination may be different among farms of the same region and different producer regions [22,23]. In the current study, $43 \mathrm{~A}$. flavus isolates were identified from the fungal cultures previously isolated from maize and soil in the Makueni, Nyeri, Bungoma, and Uasin Gishu Districts in Kenya. The highest incidence (63\%) of A. flavus was found in the maize samples from Makueni in the Eastern province, and the lowest $(5 \%)$ was found in the samples from Nyeri in the Central province. Uasin Gishu (Rift Valley) and Bungoma (Western) comprised $21 \%$ and $11 \%$ of the A. flavus isolates in this study, respectively. The differences in the occurrence of $A$. flavus in the various districts could have been due to the diversity in environmental conditions among those districts. According to Cotty and Jaime-Garcia [13], crops grown in warm climates have a greater probability of infection by aflatoxin producers, and, in some regions, infection only occurs when temperatures rise in association with drought. Makueni is characterized by temperatures of about 25 to $35^{\circ} \mathrm{C}$ and drier conditions, which favour the infection of crops by A. flavus. In a previous study, Muthomi et al. [12] reported that higher levels of $A$. flavus were found in samples of maize and maize products from semi-arid regions than were found in samples from the humid North Rift region of Kenya. The results of this study are also in agreement with those of Odhiambo et al. [14], in which the highest incidence of A. flavus was recorded in the soil and maize samples from the semi-arid Makueni District compared to the sub-humid Bungoma and humid Uasin Gishu and Nyeri.

\subsection{Morphological Identification of A. flavus}

The classical characterization of fungal species by examining several morphological traits and microscopic characteristics observed in fungal cultures grown on different media, is the oldest and most widely used tool for fungal identification. In the current study, morphological characterization was performed to emphasize the need for such basic identification approaches for the rapid screening of isolates in most developing countries, where the availability of advanced technologies is still a challenge. With the aid of the taxonomic key descriptions, it was possible to achieve a reliable identification of $A$. flavus in this study. The cultural characteristics of the isolates such as the colony colour, texture, and margins and the presence of exudates and sclerotia were examined in five different culture media. The colour, texture, and margins of the A. flavus colonies were common to all the culture media. Generally, the isolates had yellowish-green, dark-green, or olive colonies encircled by a white border, which ultimately was overlapped by conidia. The surfaces of the colonies were velvety to woolly in texture, often with a floccose centre. The isolates produced exudates on three of the five media that were used. The sclerotia were also detected on three of the five media used but were not produced by all the isolates. Sclerotia production has been reported to be a rare characteristic of $A$. flavus, although it is one of its identifying characteristics. In accordance with the taxonomic descriptions by Klich [8] and Clayton [15], the colony morphology of the isolates in this study resembled that of A. flavus, as illustrated in Figure 2.

Some species of Aspergillus have the same morphological features, and this makes it difficult to distinguish between them and A. flavus. It is known to have the same colony colour as A. oryzae. 
This renders the need for comprehensive scrutiny using microscopic and macroscopic characteristics for correct identification and classification. However, there is a consensus that, even microscopically, some characteristics are common amongst the Aspergillus isolates. The characteristics of the conidiophores, vesicles, sterigmata, and conidia were evaluated in this study. The peculiar characteristics for $A$. flavus were the globose vesicles with radiate sterigmata and rough conidiophore walls. Another important diagnostic feature was the relatively thin walls of the globose conidia, which were fine to moderately rough. These characteristics, shown in Figure 1, and the macroscopic characteristics, were in harmony with the $A$. flavus characteristics previously described [6,9].

In this study, the use of RBCA, CZA, PDA, MEA, and SDA provided adequate growth and sporulation, which allowed sufficient assessment of the macroscopic and microscopic characteristics of the fungal isolates. Using these growth media, A. flavus isolates were successfully identified. A review of the literature reveals that these and other differential growth media have primarily been employed for the morphological characterization and identification of Aspergillus species. Aspergillus species were identified from maize kernels through their morphological characterization on CZA, MEA, and PDA [24]. Using CZA and MEA, Reddy et al. [25] identified and distinguished five Aspergillus species isolated from rice grains in South Asia. Similarly, species of the Aspergillus section Flavi isolated from maize in North-eastern China were identified following the assessment of their macroscopic and microscopic characteristics on CZA and MEA [26]. Diba et al. [9] successfully identified Aspergillus species from environmental and clinical specimens by examining their morphological characteristics and reported that the use of potato dextrose, malt extract, or similar sporulation agars as primary isolation media for Aspergillus might accelerate the growth rate and the production of conidia. Morphological methods were employed for the identification of Aspergillus species from the soils of the Fars and Kerman provinces of Iran [27] and the soil of the Larkana district in Pakistan [28].

Aspergillus flavus has been divided into two strains based on the size of sclerotia; the L strain, which produces large sclerotia, and the S strain, which produces small sclerotia. The correlation between sclerotial production/size and aflatoxigenicity has been studied, and published data are contradictory. While Cotty [29] reported a direct correlation between high aflatoxin production and the presence of small sclerotia, Abbas et al. [30] found that the highest levels of aflatoxins were produced in isolates with large sclerotia. Some studies found no correlation between sclerotial production/size and aflatoxigenicity [31,32]. In this study, the size of sclerotia was not determined and aflatoxins were not quantified, and, as a result, no correlation was made between aflatoxigenicity and sclerotial type. Notwithstanding, in Kenya, the S strain is reportedly more prevalent than the L strain and has been associated with the repeated outbreaks of severe maize contamination and deaths in human populations, especially in Eastern Kenya [13,33,34].

\subsection{Discrimination between Aflatoxin-Producing and Non-Producing Isolates and Identification of Aflatoxins}

The screening for aflatoxin production was carried out based on the fluorescence of positive colonies upon exposure to UV radiation at $365 \mathrm{~nm}$. When exposed to UV light, aflatoxin-producing isolates exhibited a blue fluorescence on the undersides of the colonies, whereas the non-producing isolates did not produce any fluorescence (Figure 3). Using YES, YSCD, and CAM, it was possible to discriminate between aflatoxin-producing and non-aflatoxin-producing A. flavus isolates in this study. These culture media showed similar patterns in terms of the total number of colonies showing fluorescence upon exposure to UV radiation. Fluorescence was detected in 10 of the 43 isolates under study, indicating aflatoxin-producing potential.

In many developing countries, where the determination of aflatoxin production could be impeded by the lack of advanced discriminative tools, culture-dependent approaches could be useful for the rapid screening of isolates. Inexpensive and relatively simple as they are, however, cultural methods for aflatoxin detection have been reported to be less sensitive and are commonly used in conjunction with chromatographic methods [35]. In this study, TLC was used for the confirmation of aflatoxin production by the isolates and the identification of the aflatoxins. TLC is one of the most widely 
used separation techniques in aflatoxin analysis. The aflatoxins are well suited for analysis by TLC since most of the compounds fluoresce strongly under long-wave UV light [36]. With TLC, aflatoxin, observed under UV light as blue fluorescent spots on the developed silica gel plates, was detected in $13(30 \%)$ of the 43 A. flavus isolates in this study. Of these 13 aflatoxigenic isolates, ten tested positive for aflatoxin production during UV fluorescence screening on YES, YSCD, and CAM. Although isolates EM323, EM167, and EM291 tested negative for aflatoxin production during UV fluorescence screening, they were found to produce aflatoxin when analysed with TLC. This suggests that these isolates did not produce a high enough amount of aflatoxin to be detected by fluorescence screening. This suggestion is based on the findings by Abbas et al. [37], who, when comparing cultural and analytical methods, discovered that cultural methods are generally not as sensitive as chromatographic methods. Abbas et al. [37] reported that TLC could detect an aflatoxin concentration as low as $2.5 \mathrm{ng} / \mathrm{g}$, while, with fluorescence, aflatoxin can only be detected in cultures capable of producing greater than $61 \mathrm{ng} / \mathrm{g}$. According to Afsah-Hejri et al. [38], it has repeatedly been reported that the results from the UV fluorescence screening on media do not always correspond to the results of aflatoxin detection by chromatography.

Studies conducted in the United States revealed that all members of A. flavus lack the ability to produce $G$ aflatoxins due to some deletion in the aflatoxin biosynthesis gene cluster [39]. However, in Africa, an unnamed taxon (called strain $S_{B G}$ ) capable of producing both $B$ and $G$ aflatoxins exists and is morphologically similar to but phylogenetically divergent from the $B$ aflatoxin-producing A. flavus $S$ strains [40]. This taxon was commonly implicated in contamination events in West Africa [40], but no literature exists that associates the taxon with the contamination events in East Africa. In this study, three aflatoxin types, AFB1, AFB2, and AFG1, were identified with TLC. Isolates EM 184, EM 323, EM 213, EM 181, and EM 223 produced only AFB1, while isolates EM 267, EM291, and BS116 and isolates EM 124, EM 232, EM 257, EM 165 produced AFB2 and AFG1 in addition to AFB1, respectively (Table 1). According to Probst et al. [41], the maize growing regions in several districts of the Eastern Province of Kenya are dominated by the AFB1-producing A. flavus S strain. It is reported that this strain, although phylogenetically distinct from the USA and Asian A. flavus S strains and more closely related to the West African B and $G$ aflatoxin-producing taxon, is incapable of producing $\mathrm{G}$ aflatoxins. According to Okun et al. [42], DNA-based phylogenies revealed strain $S_{\mathrm{BG}}$ to be a distinct species, ancestral to both A. flavus and A. parasiticus. It is possible that this taxon is extant in the soils of the Eastern Kenya. Further research is necessary to confirm this hypothesis.

Notwithstanding the positive results obtained in the current study, some drawbacks were encountered during the identification of aflatoxins on TLC. When identifying aflatoxins on TLC, the $\mathrm{Rf}$ values of the samples are normally compared, with the Rf values of the aflatoxin standard being prepared with the same solvent used for the sample extract and developed side by side on one TLC plate. However, in this study, due to the unavailability of standards, the Rf values of the samples were compared to the Rf values of the standards reported by Younis and Malik [20]. In this study, the Rf values of AFB1, AFB2, and AFG1 were 0.60, 0.55, and 0.50, respectively, while Younis and Malik [20] obtained 0.55 for AFB1, 0.50 for AFB2, and 0.45 for AFG1. It has been reported that, when similar compounds are extracted using the same extraction method and developed on TLC using the same stationary and mobile phase, they are likely to have the same Rf values [43]. The difference in the $\mathrm{Rf}$ values could be because the aflatoxin extracts in the current study were not further purified and concentrated before being developed on TLC.

It should be noted, however, that, although the methods used in the current study could identify the aflatoxin-producing potential of the isolates, they are not sensitive enough for the detail identification and quantification of the toxins and therefore should be used more specifically for initial screening. For accurate quantification of the aflatoxins produced, a more sensitive and reliable method like high-performance liquid chromatography with fluorescence detection (HPLC-FLD) will be needed [44]. Similarly, although it has been reported that some strains of $A$. flavus could produce both B and G aflatoxins [45], recent classifications of Aspergillus section Flavi have noted that such strains, 
though morphologically similar to A. flavus, were completely novel species $[46,47]$. These findings point to the fact that advanced molecular techniques are needed to characterize the various Aspergillus spp. conclusively.

\subsection{Distribution of Aflatoxin Production across the Selected Districts}

Aflatoxin was detected in $28 \%$ of the isolates from Makueni and in only $2 \%$ of the isolates from Bungoma and was not detected in the isolates from Nyeri and Uasin Gishu (Figure 4). These findings suggest that the inocula of the aflatoxin-producing A. flavus are more prevalent in Eastern Kenya and that the conditions in the semi-arid region of the Eastern Province are more conducive for aflatoxin formation than the conditions in the humid regions of the Central, Rift Valley, and Western Provinces. These findings are corroborated by the fact that the Eastern Province of Kenya has experienced several outbreaks of acute aflatoxicosis since 1978, and, according to the literature, the recent and most severe outbreak was caused by $A$. flavus communities with the highest aflatoxin-producing potential ever reported [34].

No aflatoxin was detected in the samples from the Central and Rift Valley Provinces in this study. However, this does not indicate that the toxigenic strains of $A$. flavus are not present in these provinces. In the Central Province, aflatoxicosis outbreaks have previously been reported in Thika, a district adjacent to the 'aflatoxin hotspot' districts of the Eastern Province [48]. Toxigenic strains of $A$. flavus have also been detected previously in maize samples from the Rift Valley Province [49]. Aspergillus flavus has multiple strains that differ in their aflatoxin-producing capacity. Therefore, maize in different regions may become contaminated with different strains, resulting in different aflatoxin contamination frequencies.

\section{Conclusions}

In conclusion, the culture media and the taxonomic keys used in this study allowed for the precise and reliable identification of $A$. flavus. The macroscopic and microscopic characteristics were like those described in published research. The use of UV fluorescence screening and TLC for the detection and identification of aflatoxins provides a quick and reliable means to distinguish between the aflatoxigenic and non-aflatoxigenic strains of $A$. flavus. The relatively low proportion of aflatoxin-producing isolates obtained in the current study, compared to other studies, could be due to the sensitivity of the methods used, and this could result in the underestimation of the actual population of aflatoxigenic species in a given area. Nevertheless, given the high toxicity of the aflatoxins, especially AFB1, the study showed that traditional methods could be used for earlier detection of Aspergilli in crops, especially in less economically developed African countries, where advanced techniques are not readily available or accessible. The high incidences of $A$. flavus and aflatoxins in maize from Makueni in this study support the many reports of the prevalence of the highly toxic strains of A. flavus in Eastern Kenya. This further reinforces the need for measures to prevent the fungal contamination of maize and emphasises the paramount importance of field interventions aimed at curbing agricultural soil contamination by these fungi.

Acknowledgments: The authors would like to thank Hubs and Spokes, the National Research Foundation (NRF), and the Vaal University of Technology (VUT) for financial support in the form of a scholarship. We also thank the VUT for providing the necessary laboratory space and equipment for carrying out the study. However, the opinions expressed and the conclusions arrived at are those of the authors and are not necessarily to be attributed to Hubs and Spokes, the NRF, or the VUT.

Author Contributions: M.G.T. and H.M. were involved in the laboratory work. All the authors contributed equally to the writing of this paper.

Conflicts of Interest: The authors declare that they have no conflicts of interest. 


\section{References}

1. Abbas, H.; Wilkinson, J.; Zablotowicz, R.; Accinelli, C.; Abel, C.; Bruns, H.; Weaver, M. Ecology of Aspergillus flavus, regulation of aflatoxin production, and management strategies to reduce aflatoxin contamination of corn. Toxin Rev. 2009, 28, 142-153. [CrossRef]

2. Amaike, S.; Keller, N.P. Aspergillus flavus. Annu. Rev. Phytopathol. 2011, 49, 107-133. [CrossRef] [PubMed]

3. Hell, K.; Mutegi, C. Aflatoxin control and prevention strategies in key crops of Sub-Saharan Africa. Afr. J. Microbiol. Res. 2011, 5, 459-466.

4. $\mathrm{Yu}, \mathrm{J}$. Current understanding on aflatoxin biosynthesis and future perspective in reducing aflatoxin contamination. Toxins 2012, 4, 1024-1057. [CrossRef] [PubMed]

5. Klueken, A.; Borgemeister, C.; Hau, B. Field release of a non-toxigenic Aspergillus flavus L strain in Central Benin. J. Plant Dis. Prot. 2009, 116, 17-22. [CrossRef]

6. Rodrigues, P.; Soares, C.; Kozakiewicz, Z.; Paterson, R.R.M.; Lima, N. Identification and characterization of Aspergillus flavus and aflatoxins. In Communicating Current Research and Educational Topics and Trends in Applied MIcrobiology; Méndez-Vilas, A., Ed.; FORMATEX: Badajoz, Spain, 2007; pp. 527-534.

7. Cardwell, K.F.; Cotty, P.J. Distribution of Aspergillus section Flavi among field soils from the four agroecological zones of the Republic of Bénin, West Africa. Plant Dis. 2002, 86, 434-439. [CrossRef]

8. Klich, M.A. Identification of Common Aspergillus Species; Centraalbureau voor Schimmelcultures: Utrecht, The Netherlands, 2002; pp. 426-432.

9. Diba, K.; Rezaie, S.; Mahmoudi, M.; Kordbacheh, P.; Diba, C.K. Identification of Aspergillus species using morphological characteristics. Pak. J. Med. Sci. 2007, 23, 867-872.

10. Yu, J.; Bhatnagar, D.; Ehrlich, K.C. Aflatoxin biosynthesis. Rev. Iberoam. Micol. 2002, 19, 191-200. [PubMed]

11. Cotty, P.J.; Mellon, J.E. Ecology of aflatoxin-producing fungi and biocontrol of aflatoxin contamination. Mycotoxin Res. 2006, 22, 110-117. [CrossRef] [PubMed]

12. Muthomi, J.; Mureithi, B.; Chemining'wa, G.; Gathumbi, J.; Mutit, E. Aspergillus species and Aflatoxin b1 in soil, maize grain and flour samples from semi-arid and humid regions of Kenya. Int. J. Agric. Sci. 2012, 2, 22-34.

13. Probst, C.; Njapau, H.; Cotty, P.J. Outbreak of an acute aflatoxicosis in Kenya in 2004: Identification of the causal agent. Appl. Environ. Microbiol. 2007, 73, 2762-2764. [CrossRef] [PubMed]

14. Odhiambo, B.O.; Murage, H.; Wagara, I.N. Isolation and characterisation of aflatoxigenic Aspergillus species from maize and soil samples from selected counties of Kenya. Afr. J. Microbiol. Res. 2013, 7, 4379-4388.

15. Clayton, Y.M. Medically Important Fungi: A Guide to Identification. Proc. R. Soc. Med. 1977, 70, 359.

16. Riddell, R.W. Permanent stained mycological preparations obtained by slide culture. Mycologia 1950, 40, 265-270. [CrossRef]

17. Davis, N.D.; Diener, U.L.; Eldridge, W. Production of aflatoxins B1 and G1 by Aspergillus flavus in a semisynthetic medium. Appl. Environ. Microbiol. 1966, 14, 378-380.

18. Fente, C.A.; Ordaz, J.J.; Vazquez, B.I.; Franco, C.M.; Cepeda, A. New additive for culture media for rapid identification of aflatoxin-producing Aspergillus strains. Appl. Environ. Microbiol. 2001, 67, 4858-4862. [CrossRef] [PubMed]

19. Davis, N.; Iyer, S.; Diener, U. Improved method of screening for aflatoxin with a coconut. Appl. Environ. Microbiol. 1987, 53, 1593-1595. [PubMed]

20. Younis, Y.M.H.; Malik, K.M. TLC and HPLC assays of aflatoxin contamination in Sudanese peanuts and peanut products. Kuwait J. Sci. Eng. 2003, 30, 79-94.

21. Ramesh, J.; Sarathchandra, G.; Sureshkumar, V. Analysis of feed samples for aflatoxin B1 contamination by HPTLC: A validated method. Int. J. Curr. Microbiol. Appl. Sci. 2013, 2, 373-377.

22. Da Gloria, M.E. Aflatoxin contamination distribution among grains and nuts. In Aflatoxins-Detection, Measurement and Control; Torres-Pacheco, I., Ed.; InTech: Rijeka, Croatia, 2011; pp. 75-90.

23. Cotty, P.J.; Jaime-Garcia, R. Influences of climate on aflatoxin-producing fungi and aflatoxin contamination. Int. J. Food Microbiol. 2007, 119, 109-115. [CrossRef] [PubMed]

24. Askun, T. Investigation of fungal species of maize kennels. J. Biol. Sci. 2006, 6, 275-281. [CrossRef]

25. Reddy, K.R.N.; Abbas, H.K.; Abel, C.A.; Shier, W.T.; Salleh, B. Mycotoxin Contamination of Beverages: Occurrence of Patulin in Apple Juice and Ochratoxin A in Coffee, Beer and Wine and Their Control Methods. Toxins 2010, 2, 229-261. [CrossRef] 
26. Gao, J.; Liu, Z.; Yu, J. Identification of Aspergillus section Flavi in maize in northeastern China. Mycopathologia 2007, 164, 91-95. [CrossRef] [PubMed]

27. Mohammadi, A.H.; Banihashemi, Z.; Haghdel, M. Identification and prevalence of Aspergillus species in soils of fars and Kerman provinces of Iran and evaluation of their aflatoxin production. Rostanilha 2009, 10, 23.

28. Afzal, H.; Shazad, S.; Qamar, S.; Nisa, U. Morphological identification of Aspergillus species from the soil of Larkana District (Sindh, Pakistan). Asian J. Agric. Biotechnol. 2013, 1, 105-117.

29. Cotty, P.J. Virulence and cultural characteristics of two Aspergillus flavus strains pathogenic on cotton. Phytopathology 1989, 79, 808-814. [CrossRef]

30. Abbas, H.K.; Weaver, M.A.; Zablotowicz, R.M.; Horn, B.W.; Shier, W.T. Relationships between aflatoxin production and sclerotia formation among isolates of Aspergillus section Flavi from the Mississippi Delta. Eur. J. Plant Pathol. 2005, 112, 283-287. [CrossRef]

31. Giorni, P.; Magan, N.; Pietri, A.; Bertuzzi, T.; Battilani, P. Studies on Aspergillus section Flavi isolated from maize in northern Italy. Int. J. Food Microbiol. 2007, 113, 330-338. [CrossRef] [PubMed]

32. Baquião, A.C.; De Oliveira, M.M.M.; Reis, T.A.; Zorzete, P.; Diniz Atayde, D.; Correa, B. Polyphasic approach to the identification of Aspergillus section Flavi isolated from Brazil nuts. Food Chem. 2013, 139, 1127-1132.

33. Probst, C.; Schulthess, F.; Cotty, P.J. Impact of Aspergillus section Flavi community structure on the development of lethal levels of aflatoxins in Kenyan maize ( Zea mays ). J. Appl. Microbiol. 2010, 108, 600-610. [CrossRef] [PubMed]

34. Probst, C.; Bandyopadhyay, R.; Price, L.E.; Cotty, P.J. Identification of atoxigenic Aspergillus flavus isolates to reduce aflatoxin contamination of maize in Kenya. Plant Dis. 2011, 95, 212-218. [CrossRef]

35. Abbas, H.K.; Shier, W.T.; Horn, B.W.; Weaver, M.A. Cultural methods for aflatoxin detection. J. Toxicol. Toxin Rev. 2004, 23, 295-315. [CrossRef]

36. Wacoo, A.P.; Wendiro, D.; Vuzi, P.C.; Hawumba, J.F. Methods for detection of aflatoxins in agricultural food crops. J. Appl. Chem. 2014, 2014, 1-15. [CrossRef]

37. Abbas, H.K.; Zablotowicz, R.M.; Weaver, M.A.; Horn, B.W.; Xie, W.; Shier, W.T. Comparison of cultural and analytical methods for determination of aflatoxin production by Mississippi Delta Aspergillus isolates. Can. J. Microbiol. 2004, 50, 193-199. [CrossRef] [PubMed]

38. Afsah-Hejri, L.; Jinap, S.; Radu, S. Occurrence of aflatoxins and aflatoxigenic Aspergillus in peanuts. J. Food Agric. Environ. 2013, 11, 228-234.

39. Ehrlich, K.C.; Chang, P.-K.; Yu, J.; Cotty, P.J. Aflatoxin biosynthesis cluster gene cypA is required for G aflatoxin formation. Appl. Environ. Microbiol. 2004, 70, 6518-6524. [CrossRef] [PubMed]

40. Atehnkeng, J.; Ojiambo, P.S.; Donner, M.; Ikotun, T.; Sikora, R.A.; Cotty, P.J.; Bandyopadhyay, R. Distribution and toxigenicity of Aspergillus species isolated from maize kernels from three agro-ecological zones in Nigeria. Int. J. Food Microbiol. 2008, 122, 74-84. [CrossRef] [PubMed]

41. Probst, C.; Callicott, K.A.; Cotty, P.J. Deadly strains of Kenyan Aspergillus are distinct from other aflatoxin producers. Eur. J. Plant Pathol. 2012, 132, 419-429. [CrossRef]

42. Okun, D.O.; Khamis, F.M.; Muluvi, G.M.; Ngeranwa, J.J.; Ombura, F.O.; Yongo, M.O.; Kenya, E.U. Distribution of indigenous strains of atoxigenic and toxigenic Aspergillus flavus and Aspergillus parasiticus in maize and peanuts agro-ecological zones of Kenya. Agric. Food Secur. 2015, 4, 14. [CrossRef]

43. Hussain, I. Aflatoxin Measurement and Analysis. In Aflatoxins-Detection, Measurement and Control; Torres-Pacheco, I., Ed.; InTech: Rijeka, Croatia, 2011; pp. 183-203.

44. Di Stefano, V.; Pitonzo, R.; Avellone, G.; Di Fiore, A.; Monte, L.; Ogorka, A.Z.T. Determination of aflatoxins and ochratoxins in Sicilian sweet wines by high-performance liquid chromatography with fluorometric detection and immunoaffinity cleanup. Food Anal. Methods 2015, 8, 569-577. [CrossRef]

45. Takahashi, H.; Kamimura, H.; Ichinoe, M. Distribution of aflatoxin-producing Aspergillus flavus and Aspergillus parasiticus in sugarcane fields in the southernmost islands of Japan. J. Food Prot. 2004, 67, 90-95. [CrossRef] [PubMed]

46. Varga, J.; Frisvad, J.C.; Samson, R.A. Two new aflatoxin producing species, and an overview of Aspergillus section Flavi. Stud. Mycol. 2011, 69, 57-80. [CrossRef] [PubMed]

47. Pildain, M.B.; Frisvad, J.C.; Vaamonde, G.; Cabral, D.; Varga, J.; Samson, R.A. Two novel aflatoxin-producing Aspergillus species from Argentinean peanuts. Int. J. Syst. Evol. Microbiol. 2008, 58, 725-735. [CrossRef] [PubMed] 
48. Centers for Disease Control and Prevention (CDC). Outbreak of aflatoxin poisoning-Eastern and central provinces, Kenya, January-July 2004. MMWR 2004, 53, 790-793.

49. Okoth, S.; Nyongesa, B.; Ayugi, V.; Kan'gethe, E.; Korhonen, H.; Joutsjoki, V. Toxigenic potential of Aspergillus species occurring on maize kernels from two agro-ecological zones in Kenya. Toxins 2012, 4, 991-1007. [CrossRef] [PubMed] 